\title{
Incidence of tuberculous meningitis in the State of Santa Catarina, Brazil
}

\author{
Cíntia Helena de Souza ${ }^{[1]}$, Ayaka Yamane ${ }^{[1]}$, Jeison Cleiton Pandini ${ }^{[1]}$, \\ Luciane Bisognin Ceretta ${ }^{[2]}$, Fabiane Ferraz ${ }^{[2]}$, Glauco Duarte da Luz ${ }^{[1]}$ \\ and Priscyla Waleska Simões ${ }^{[1],[3],[4]}$
}

\begin{abstract}
[1]. Curso de Medicina, Unidade Acadêmica de Ciências da Saúde, Universidade do Extremo Sul Catarinense, Criciúma, SC. [2]. Grupo de Pesquisa em Gestão do Cuidado, Integralidade e Educação na Saúde, Laboratório de Direito Sanitário e Saúde Coletiva, Curso de Enfermagem, Unidade Acadêmica de Ciências da Saúde, Universidade do Extremo Sul Catarinense, Criciúma, SC. [3]. Grupo de Pesquisa em Epidemiologia, Unidade Acadêmica de Ciências da Saúde, Universidade do Extremo Sul Catarinense, Criciúma, SC. [4]. Grupo de Pesquisa em Tecnologia da Informação e Comunicação na Saúde, Unidade Acadêmica de Ciências, Engenharias e Tecnologias, Universidade do Extremo Sul Catarinense, Criciúma, SC.
\end{abstract}

\begin{abstract}
Introduction: The aim of this study was to estimate the incidence of tuberculous meningitis in the State of Santa Catarina (SC), Brazil, during the period from 2001 to 2010. Methods: Ecological, temporal, and descriptive methods were employed using data obtained from the Information System on Disease Notification (Sistema de Informação de Agravos de Notificação). Results: One hundred sixteen reported cases of tuberculous meningitis occurred from 2001 to 2010 , corresponding to $1.2 \%(0.2$ cases $/ 100,000$ inhabitants) of all meningitis cases reported in SC. There was a predominance of new cases in males, corresponding to $56.9 \%$ of new cases $(0.2$ cases $/ 100,000$ inhabitants; males vs. females; $p=0.374)$, in patients aged $20-39$ years, corresponding to $52.6 \%$ of new cases $(0.5$ cases $/ 100,000$ inhabitants; 20 -39 years versus others; $p<0.001)$, and in urban areas, corresponding to $91.4 \%$ of new cases $(0.2$ cases $/ 100,000$ inhabitants; urban vs. rural; $\mathrm{p}=0.003)$. In $48.3 \%$ of cases, the outcome was death. Conclusions: The incidence rate of tuberculous meningitis in SC has increased within the last decade, with the most affected population comprising young adult white males with an average education. Thus, tuberculous meningitis remains a serious disease, emphasizing the need for disease prevention with vaccination campaigns against tuberculosis, the development of faster and more accurate diagnostic methods, and the use of current epidemiological knowledge regarding the disease to facilitate the establishment of early treatment.
\end{abstract}

Keywords: Incidence. Epidemiology. Meningeal tuberculosis. Brazil.

\section{INTRODUCTION}

Meningitis occurs when an inflammatory process affects the meninges, the cerebrospinal fluid (CSF), and the subarachnoid space. When the brain tissue is surrounded by a viral infection, the disease is called encephalitis, whereas infections caused by other etiological agents involving the brain are called cerebritis or an abscess, based on the presence or absence of a capsule $e^{1,2}$.

Meningitis is classified as acute, subacute, or chronic, based on the time course of the inflammatory process. The speed of development relates to the nature of the infecting organism ${ }^{3}$. The clinical syndrome found in subacute meningitis differs from that found in acute purulent meningitis because the onset

Address to: Dr ${ }^{\text {a }}$ Priscyla Waleska Targino de Azevedo Simões. Curso de Medicina/UNASAU/UNESC. Av. Universitária 1105, Bairro Universitário, 88803-110 Criciúma, SC, Brasil.

Phone: 5548 3431-2641

e-mail: pri@unesc.net

Received 21 May 2014

Accepted 30 July 2014 of symptoms typically has a more protracted evolution for the latter, and the degree of the inflammatory reaction yields complications, such as hydrocephalus, intracranial hypertension, cerebral vascular infarction, cranial nerve palsies, and death ${ }^{4-6}$. Subacute meningitis is a pathology that is difficult to diagnose because its clinical presentation is highly varied. The available diagnostic methods do not exhibit the necessary speed and sensitivity for the immediate and precise introduction of specific treatments, and a high degree of suspicion from the physician is required to reach a diagnosis for this disease classification?

Tuberculous meningitis (TBM) is a serious infection of the central nervous system (CNS) and is classified as a subacute meningitis ${ }^{3,7}$. The invasion of a microorganism into the CNS parenchyma or its meninges induces an inflammatory reaction that includes plasmatic exudation and the proliferation of vasculo-conjunctive and hematogenic elements, leading to cellular infiltration and parenchymal changes ${ }^{3}$. Early diagnosis is extremely important, not only because of the usually fatal outcome of the disease but also because of the neurological sequelae that commonly develop $p^{3,4,6,7}$.

Knowledge of the epidemiological profile of TBM in a certain region allows for reflection on the importance of the disease, which presents as a complication of primary 
tuberculosis (TB) occurring most frequently within the first 6 months after infection. Furthermore, TBM is the most severe clinical form of the disease, with a high mortality rate and a high frequency of serious and disabling neurological sequelae $e^{7-10}$, as found in studies conducted in Vietnam between 1997 and 2000 7 and in India between 2008 and 2009'.

Tuberculosis became a reemerging disease in developed countries in the late twentieth century and has maintained an occurrence at high levels, eventually increasing in developing countries. Twenty-two countries hold $80 \%$ of the TB cases worldwide, with an estimated prevalence of 50 million infected (i.e., approximately 109,672 new cases and 6,000 deaths per year) $)^{4,6,8,11}$.

Tuberculosis is a major global health problem, and the most common manifestation in humans is pulmonary disease; however, nearly all organ systems can be involved. More than $95 \%$ of cases and $98 \%$ of deaths in the world occur in developing countries. Meningeal TB in children and TB occurring in people coinfected with human immunodeficiency virus (HIV) are important causes of death in areas of high TB prevalence ${ }^{12}$.

Globally, Brazil ranks $14^{\text {th }}$ in its number of TB cases, and this disease is the ninth leading cause of hospitalization and the fourth leading cause of mortality from infectious diseases in Brazil. According to the Information System on Disease Notification of the Ministry of Health (SINAN/MS - Sistema de Informação de Agravos de Notificação do Ministério da Saúde), the total number of cases registered in 2005 was 87,233. Among them, $88.4 \%(77,120)$ were new cases of TB in all forms, and $14.4 \%$ of these cases were extrapulmonary, whereas TB involving the brain occurred in less than $5 \%$ of cases ${ }^{4,6,8,11}$.

TB coinfection with HIV causes higher rates of mortality than does HIV infection alone. Anti-TB drug resistance and increased risk of transmission are problems that have arisen because of noncompliance with TB therapies ${ }^{6,11-14}$. It has been shown that HIV-infected patients have a higher risk of reactivation of a latent TB infection due to a poor immune response, with acquired immunodeficiency syndrome (AIDS) being a strong risk factor for death in TB patients ${ }^{4,7,13,14}$. Associated with these factors, TB remains the most important infectious cause of death worldwide, and it is possible that the most affected population consists of chronically ill or immunesuppressed individuals due to their greater susceptibility to infection by such etiological agents s-7,11-14 $^{5}$

In Brazil, approximately 20,000 new cases of HIV are reported per year, with the prevalence of infected individuals estimated to be approximately 600,000 total cases. The rate of TB/HIV coinfection in 2001-2004 averaged 8.1\% ${ }^{11}$. During this period, Santa Catarina (SC) was the second state in Brazil with the highest load of TB/HIV coinfection, where in adults, TBM is presented among the TB cases that promote coinfection and are characterized as a major public health problem ${ }^{11}$.

In this context, the present study aimed to estimate the TBM incidence in SC, Brazil, during the period from 2001 to 2010.

\section{METHODS}

This investigation is a temporal, descriptive, and ecological study that was approved by the Ethics Committee for Research Involving Human Subjects, and the research was conducted under protocol $172 / 2011$. We used the $10^{\text {th }}$ edition of the International Statistical Classification of Diseases and Related Health Problems (ICD 10) related to the A17.0 event, which represents TBM.

The population consisted of TBM cases recorded in SINAN/ MS during the period 2001-2010, involving individuals residing in the State of Santa Catarina.

The population data were derived from the census conducted by the Brazilian Institute of Geography and Statistics (IBGE Instituto Brasileiro de Geografia e Estatística ${ }^{15}$.

A historical series from 2001 to 2010 was constructed from the period for which TBM notifications were available at SINAN/MS, as served by the Department of Informatics of the Unified Health System (DATASUS - Departamento de Informática do Sistema Único de Saúde).

Ages were stratified according to the following groups adopted by SINAN/MS ${ }^{16}$ : less than 1 year; 1 to 4 years; 5 to 9 years; 10 to 14 years; 15 to 19 years; 20 to 39 years; 40 to 59 years; 60 to 69 years; and 70 to 79 years. Both males and females were included in the study.

It was possible to stratify the reported cases according to urban or rural residential area. Education was stratified according to the years of formal education, as follows: none ( 0 years); 1 to 3 years; 4 to 7 years; 8 to 11 years; and 12 or more years. Due to the categorical differences presented by SINAN/MS before and after the year 2000, it was decided to combine the reported cases for individuals with elementary school education (4 to 7 years of study) and individuals with high school education ( 8 to 11 years of study) ${ }^{16}$.

The following classification was used for subject race/color: white; black; and brown ${ }^{16}$. The reported cases were assessed using the following diagnostic methods to confirm a TBM diagnosis: culture; clinical signs; bacterioscopy; necropsy; therapeutic testing; epidemiological linkage; cytochemistry; polymerase chain reaction (PCR), and other techniques. The outcome was classified as either cure or death ${ }^{16}$.

The absolute and relative frequencies for all variables were calculated. The gross incidence rate was calculated by dividing the number of reported cases by the number of residents in the same place and period, multiplied by 100,000.

We calculated the incidence coefficient, which was proportional and standardized by gender, age, education, and housing area, because data on these variables are available in SINAN/MS and IBGE, both provided by DATASUS and the State Health Secretariat of Santa Catarina, Brazil.

The data tabulation and access to SINAN/MS was performed using the TabNet program (Datasus, Brasília, Distrito Federal, Brazil)., available online in DATASUS, and by the TabWin software version 3.6 (Datasus, Brasília, Distrito Federal, Brazil). The indicators were calculated using Excel version 2010, and the 
statistical analysis was conducted using the Statistical Package for the Social Sciences - SPSS - (IBM company, Armonk, New York, United States), version 20.0.

The normal distribution of quantitative data was assessed by the Shapiro-Wilk test. An analysis of variance (ANOVA), followed by a post-hoc Tukey's test, was used to compare means between categories of the years in school variable. Student's t-test for independent samples was used to compare the averages calculated for the gender and area of residence variables.

\section{RESULTS}

During the period 2001-2010, 116 reports of TBM occurred, corresponding to $1.2 \%$ of all meningitis cases reported in the State of SC. The average gross coefficient for the analyzed years was 0.2 new cases/100,000 inhabitants. The descriptive profile of the population studied is available in Table 1 .

Throughout the study period, the most new cases of TBM occurred in males (Figure 1), with $56.9 \%(n=66)$ of new cases being male and an average coefficient of 0.2 new male cases per 100,000 inhabitants. Exceptions occurred in the years 2006
(0.1 new cases/100,000 inhabitants for both males and females), 2007 ( 0.1 new female cases/100,000 inhabitants and 0.1 new male cases/100,000 inhabitants), and 2009 (0.2 new female cases/100,000 inhabitants and 0.2 new male cases/100,000 inhabitants), when there were slight inversions and increased incidences among females. However, although our data may suggest an association between sex and the incidence of TBM during the period considered, there was no significant difference $(\mathrm{p}=0.374)$.

With respect to the age groups, we observed the highest average coefficient ( 0.5 new cases per 100,000 inhabitants) in the age group of 20 to 39 year-olds, corresponding to $52 \%$ $(n=61)$ of new cases. This group was followed by the 40 to 59 year-olds $(0.3$ new cases/100,000 inhabitants) with $28.5 \%$ $(\mathrm{n}=33)$, the 1 to 4 year-olds ( 0.2 new cases $/ 100,000$ inhabitants $)$ with $6.0 \%(n=7)$, the 60 to 69 year-olds with $5.2 \%(n=6)$, the under 1 year-olds ( 0.3 new cases/100,000 inhabitants) with $2.6 \%$ $(n=3)$, and the 5 to 9 year-olds and the 10 to 14 year-olds, both with $1.7 \%(n=2)$. The lowest average coefficients were found in the 15 to 19 year-olds and the 70 to 79 year-olds, both with rates of 0.02 new cases per 100,000 inhabitants. Thus, our findings revealed a significant association between age group and the incidence of TBM in the period considered $(p<0.001)$.

TABLE 1 - Descriptive profile of the population.

\begin{tabular}{|c|c|c|c|c|c|c|c|c|c|c|}
\hline & \multicolumn{10}{|c|}{ Variable } \\
\hline & \multicolumn{2}{|c|}{$\begin{array}{c}2001-2002 \\
n=22\end{array}$} & \multicolumn{2}{|c|}{$\begin{array}{c}2003-2004 \\
n=14\end{array}$} & \multicolumn{2}{|c|}{$\begin{array}{c}2005-2006 \\
n=13\end{array}$} & \multicolumn{2}{|c|}{$\begin{array}{c}2007-2008 \\
n=20\end{array}$} & \multicolumn{2}{|c|}{$\begin{array}{c}2009-2010 \\
n=47\end{array}$} \\
\hline & count & $\%$ & count & $\%$ & count & $\%$ & count & $\%$ & count & $\%$ \\
\hline \multicolumn{11}{|l|}{ Race } \\
\hline brown & 0 & 0.0 & 0 & 0.0 & 1 & 7.7 & 0 & 0.0 & 7 & 14.9 \\
\hline ignored/blank & 9 & 40.9 & 2 & 14.3 & 1 & 7.7 & 0 & 0.0 & 1 & 2.1 \\
\hline \multicolumn{11}{|l|}{ Sex } \\
\hline$<1$ & 0 & 0.0 & 0 & 0.0 & 2 & 15.4 & 1 & 5.0 & 0 & 0.0 \\
\hline $1-4$ & 0 & 0.0 & 1 & 7.1 & 2 & 15.4 & 2 & 10.0 & 2 & 4.3 \\
\hline $5-9$ & 0 & 0.0 & 1 & 7.1 & 0 & 0.0 & 1 & 5.0 & 0 & 0.0 \\
\hline $10-14$ & 0 & 0.0 & 0 & 0.0 & 0 & 0.0 & 1 & 5.0 & 1 & 2.1 \\
\hline $15-19$ & 1 & 4.5 & 0 & 0.0 & 0 & 0.0 & 0 & 0.0 & 0 & 0.0 \\
\hline $20-39$ & 14 & 63.6 & 6 & 42.9 & 3 & 23.1 & 9 & 45.0 & 29 & 61.7 \\
\hline $40-59$ & 6 & 27.3 & 4 & 8.6 & 6 & 46.2 & 3 & 15.0 & 14 & 29.8 \\
\hline $60-69$ & 1 & 4.5 & 1 & 7.1 & 0 & 0.0 & 3 & 15.0 & 1 & 2.1 \\
\hline
\end{tabular}


TABLE 1 - Continuation.

\begin{tabular}{|c|c|c|c|c|c|c|c|c|c|}
\hline \multicolumn{10}{|c|}{ Variable } \\
\hline 200 & & \multicolumn{2}{|c|}{$2003-2004$} & \multicolumn{2}{|c|}{$2005-2006$} & \multicolumn{2}{|c|}{$2007-2008$} & \multicolumn{2}{|c|}{ 2009-2010 } \\
\hline \multicolumn{2}{|c|}{$n=22$} & \multicolumn{2}{|c|}{$\mathrm{n}=14$} & \multicolumn{2}{|c|}{$\mathrm{n}=13$} & \multicolumn{2}{|c|}{$\mathrm{n}=20$} & \multicolumn{2}{|c|}{$\mathrm{n}=47$} \\
\hline count & $\%$ & count & $\%$ & count & $\%$ & count & $\%$ & count & $\%$ \\
\hline
\end{tabular}

Confirmation criteria

\begin{tabular}{|c|c|c|c|c|c|c|c|c|c|c|}
\hline culture & 3 & 13.6 & 0 & 0.0 & 0 & 0.0 & 1 & 5.0 & 3 & 6.4 \\
\hline clinical signs & 4 & 18.2 & 1 & 7.1 & 2 & 15.4 & 8 & 40.0 & 5 & 10.6 \\
\hline bacterioscopy & 2 & 9.1 & 0 & 0.0 & 0 & 0.0 & 2 & 10.0 & 1 & 2.1 \\
\hline necropsy & 0 & 0.0 & 0 & 0.0 & 1 & 7.7 & 0 & 0.0 & 0 & 0.0 \\
\hline therapeutic testing & 1 & 4.5 & 1 & 7.1 & 3 & 23.1 & 0 & 0.0 & 0 & 0.0 \\
\hline epidemiological linkage & 2 & 9.1 & 0 & 0.0 & 1 & 7.7 & 5 & 25.0 & 14 & 29.8 \\
\hline cytochemistry & 2 & 9.1 & 1 & 7.1 & 1 & 7.7 & 3 & 15.0 & 7 & 14.9 \\
\hline other & 7 & 31.8 & 10 & 71.4 & 5 & 38.5 & 1 & 5.0 & 13 & 27.7 \\
\hline PCR & 0 & 0.0 & 0 & 0.0 & 0 & 0.0 & 0 & 0.0 & 4 & 8.5 \\
\hline ignored/blank & 1 & 4.5 & 1 & 7.1 & 0 & 0.0 & 0 & 0.0 & 0 & 0.0 \\
\hline \multicolumn{11}{|l|}{ Outcome } \\
\hline cure & 10 & 45.5 & 5 & 35.7 & 10 & 76.9 & 10 & 50.0 & 23 & 48.9 \\
\hline death & 12 & 54.5 & 9 & 64.3 & 3 & 23.1 & 10 & 50.0 & 22 & 46.8 \\
\hline ignored/blank & 0 & 0.0 & 0 & 0.0 & 0 & 0.0 & 0 & 0.0 & 2 & 4.3 \\
\hline \multicolumn{11}{|l|}{ Residential area } \\
\hline urban & 20 & 90.9 & 12 & 85.7 & 10 & 76.9 & 20 & 100.0 & 44 & 93.6 \\
\hline rural & 1 & 4.5 & 0 & 0.0 & 1 & 7.7 & 0 & 0.0 & 1 & 2.1 \\
\hline urban/rural & 0 & 0.0 & 0 & 0.0 & 2 & 15.4 & 0 & 0.0 & 0 & 0.0 \\
\hline ignored/blank & 1 & 4.5 & 2 & 14.3 & 0 & 0.0 & 0 & 0.0 & 2 & 4.3 \\
\hline & \multicolumn{10}{|c|}{2006} \\
\hline Pregnant & & & & & \multicolumn{2}{|c|}{$\mathrm{n}=3$} & & & & \\
\hline no & - & - & - & - & 2 & 66.7 & 6 & 30.0 & 22 & 46.8 \\
\hline not applicable & - & - & - & - & 1 & 33.3 & 14 & 70.0 & 24 & 51.1 \\
\hline ignored/blank & - & - & - & - & 0 & 0.0 & 0 & 0.0 & 1 & 2.1 \\
\hline \multicolumn{11}{|l|}{ Education (years) } \\
\hline none & 0 & 0.0 & 1 & 7.1 & 0 & 0.0 & 0 & 0.0 & 1 & 2.1 \\
\hline $1-3$ & 5 & 22.7 & 3 & 21.4 & 0 & 0.0 & 1 & 5.0 & 0 & 0.0 \\
\hline $4-7$ & 12 & 54.5 & 3 & 21.4 & 6 & 46.2 & 2 & 10.0 & 3 & 6.4 \\
\hline $8-11$ & 2 & 9.1 & 4 & 28.6 & 0 & 0.0 & 8 & 40.0 & 17 & 36.2 \\
\hline$\geq 12$ & 1 & 4.5 & 0 & 0.0 & 0 & 0.0 & 3 & 15.0 & 14 & 29.8 \\
\hline not applicable & 0 & 0.0 & 2 & 14.3 & 4 & 30.8 & 3 & 15.0 & 6 & 12.8 \\
\hline ignored/blank & 2 & 9.1 & 1 & 7.1 & 3 & 23.1 & 3 & 15.0 & 6 & 12.8 \\
\hline
\end{tabular}

PCR: polymerase chain reaction. 


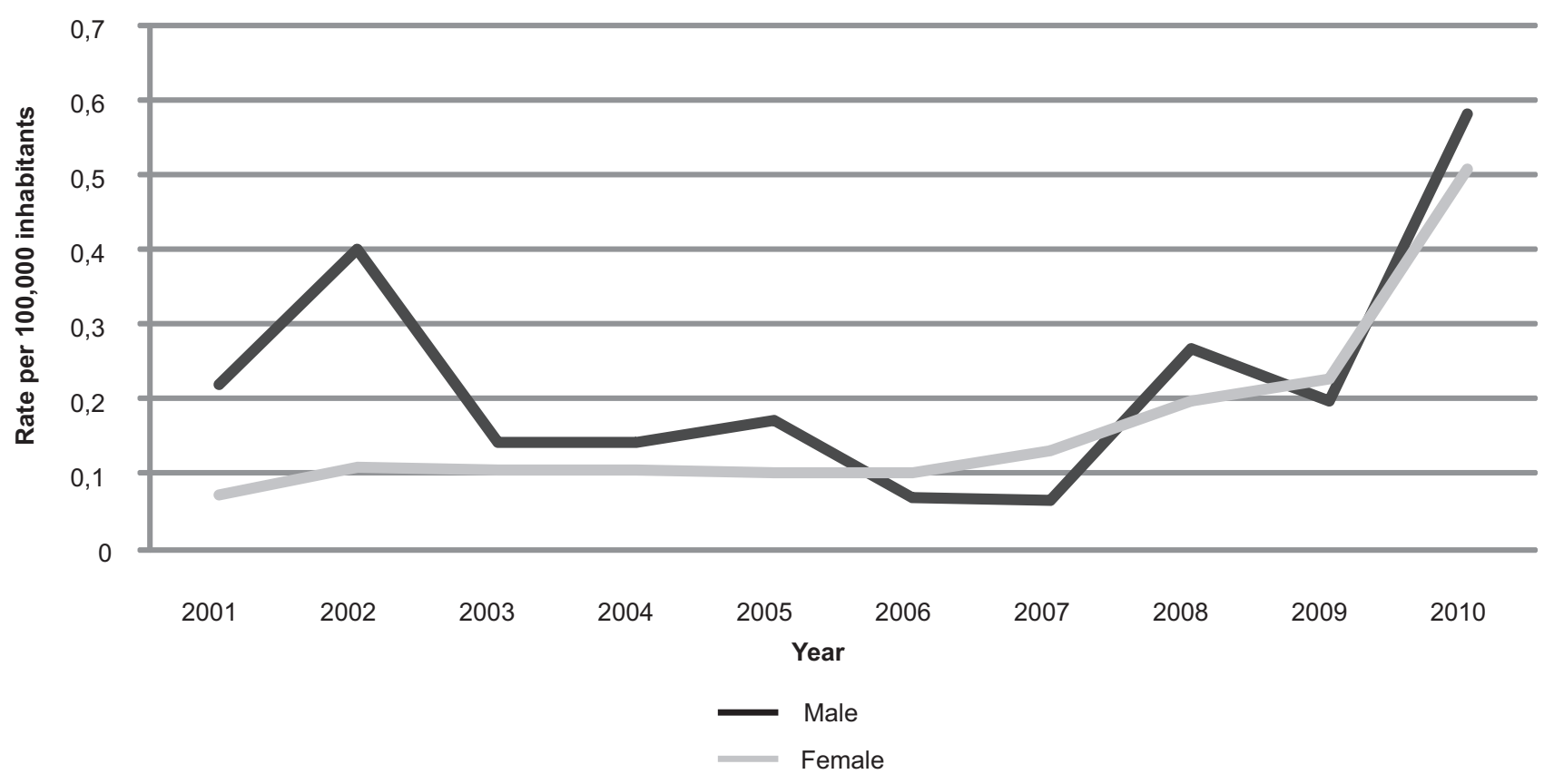

FIGURE 1 - Incidence of tuberculous meningitis by gender.

Regarding education level, we observed that individuals with 4 to 7 completed years of study had the highest average coefficient $(0.05 / 100,000$ inhabitants), followed by the subjects that completed 8 to 11 years of study $(0.04 / 100,000$ inhabitants), the subjects with 12 years or more of study $(0.03 / 100,000$ inhabitants), and the subjects with 1 to 3 years of study (0.02/100,000 inhabitants).

Among the confirmed cases of TBM, epidemiological linkage was the most common mode for confirming reported cases $(19 \% ; n=22)$, followed by clinical signs $(17.2 \% ; n=20)$, cytochemistry $(12.1 \% ; \mathrm{n}=14)$, culture $(6.0 \% ; \mathrm{n}=7)$, bacterioscopy $(4.3 \% ; n=5)$, therapeutic testing $(4.3 \% ; n=5)$, PCR $(3.5 \% ; n=4)$, and ultimately, necropsy $(0.9 \% ; n=1)$. Other criteria for confirmation were used in 36 cases, corresponding to $31.0 \%$ of all cases in this study.

The urban residential area (Figure 2) showed the highest average coefficient of incidence (0.2/100,000 inhabitants), representing $91.4 \%(\mathrm{n}=106)$ of all reported cases, while the rural area revealed an average of $0.1 / 100,000$ inhabitants, representing $2.6 \%(\mathrm{n}=3)$ of all reported cases; this difference was considered significant $(p=0.003)$. However, there was an inversion of these values in 2006, with an increase in the number of new cases in rural areas associated with a decreased incidence in the urban areas. Until 2006, the rates ranged from 0 to 0.1 new cases $/ 100,000$ inhabitants in the rural areas and from 0 to 0.3 new cases $/ 100,000$ inhabitants in the urban areas. During the period between 2006 and 2010, the rates of new cases per 100,000 inhabitants ranged from 0 to 0.1 in the rural areas and from 0 to 0.6 in the urban areas.

Regarding racial differences, there was a predominance of new cases among white individuals (representing $69.0 \%$ of all reported cases; $\mathrm{n}=81)$, followed by black individuals $(12.1 \% ; \mathrm{n}=14)$ and brown individuals $(6.9 \% ; \mathrm{n}=8)$.

Cases where the outcome was death $(48.3 \%$; $n=56)$ were in a similar proportion to cases where the outcome was cure $(50 \%$; $\mathrm{n}=58$ ). However, it is noteworthy that during the study period, there were slight changes in these proportions, with a higher proportion of cured cases in 2003, 2005, 2006, 2008, and 2010.

\section{DISCUSSION}

This study revealed that during the period from 2001 to 2010,116 cases of TBM were reported, corresponding to $1.2 \%$ of all meningitis cases reported in the State of Santa Catarina, with an average gross coefficient of 0.2 new cases per 100,000 inhabitants. These data are similar to those found by the State Health Secretariat of Bahia, which showed that in the year 1995, 40 cases of TBM were recorded, with an incidence coefficient of 0.3 per 100,000 inhabitants ${ }^{17}$; similarly, another study conducted during the period from 1990 to 2000 in Salvador, Brazil, with 168 new TBM cases revealed an incidence of 0.7 per 100,000 inhabitants $^{18}$.

Table 1 shows an increase in the number of TBM cases in both sexes from 2007 to 2010 (240\% in males and 230\% in females), which corroborates the information from a study conducted in Denmark from 2000 to $2008^{5}$ that reported that the TBM incidence has increased in recent decades, a characteristic that has accompanied the rise of multi-drug-resistant TB and cases in patients with immunodeficiency ${ }^{4-6,8,11-17}$. Studies have shown that chronically ill or immunosuppressed individuals are more susceptible to infections by such etiological agents 


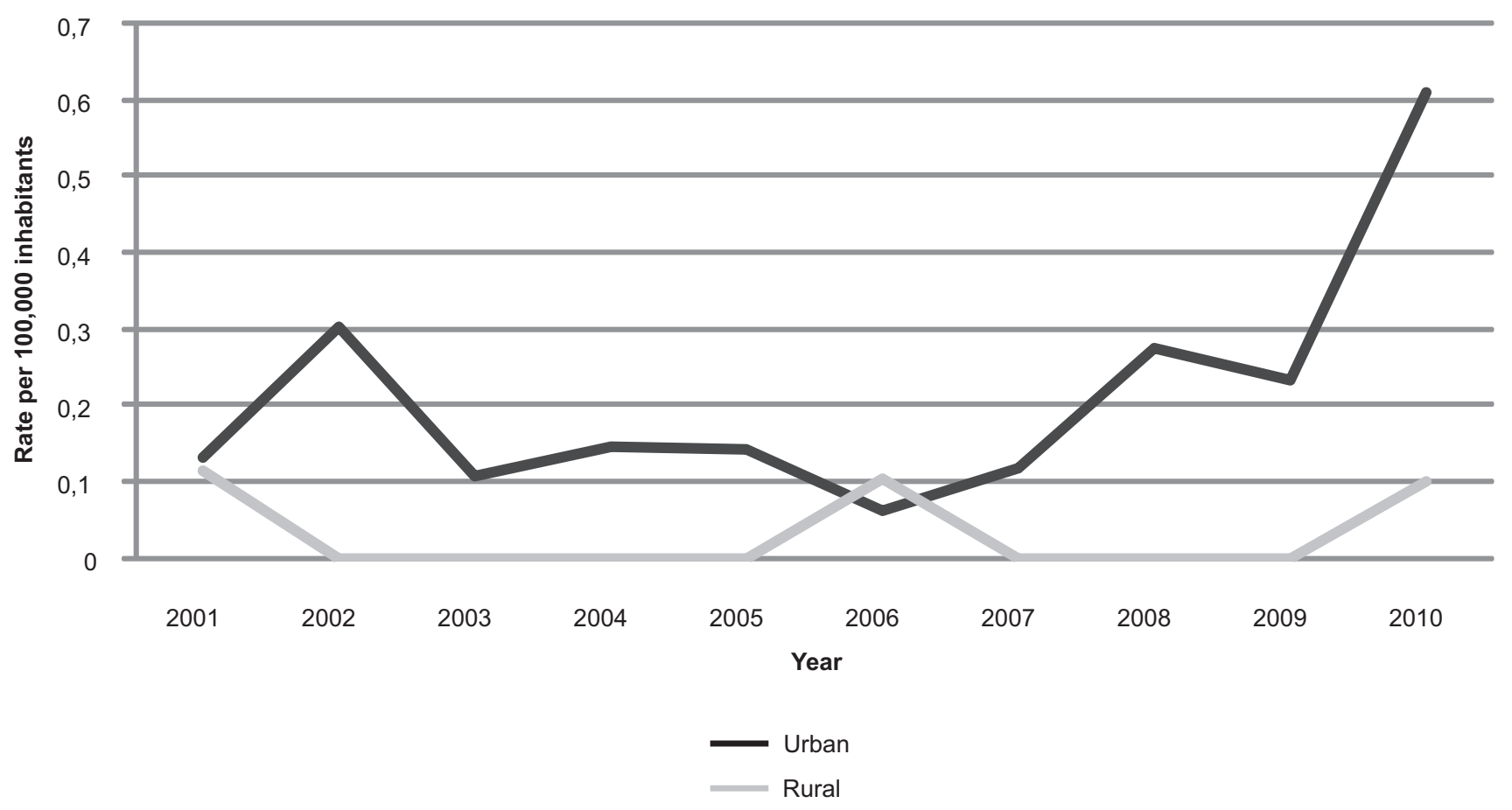

FIGURE 2 - Incidence of tuberculous meningitis by area.

compared with healthy individuals, and the situation worsened with the advent of the AIDS epidemic, which witnessed a $12 \%$ increase in TB cases in developed countries. Other risk factors such as malnutrition, poverty, recent infection by measles in children, alcoholism, cancer, diabetes, and the use of immunosuppressive agents in adults are mentioned as predisposing factors ${ }^{3-6,11-13,17}$.

In this study, a higher incidence of TBM was observed in males ( $56.9 \%$ of all new cases). This observed rate is similar to that found in a retrospective cohort study of 231 patients who began in 1983 in Salvador, Bahia, Brazil (55\%) ${ }^{8,17}$.

It was observed that $52.6 \%$ of the reported cases occurred in the group of individuals aged 20 to 39 years. This group also showed the highest incidence rate, similar to the results of research conducted in Denmark that studied two groups, one group of Danes with a mean age of 17 years (range, 1-52) and another group of immigrants with an average age of 34 years (range, 1-71). Studies have associated these sex and age groups with a higher exposure to risk factors, such as alcoholism and HIV coinfection ${ }^{5,14}$; furthermore, research conducted between 1986 and 2002 at a university hospital in Rio de Janeiro ${ }^{6}$ revealed that $31 \%$ of 42 TBM cases were HIV positive, $60 \%$ of all meningitis cases (all classes) were male, and $45.8 \%$ were individuals over 20 years of age.

Regarding the number of children affected by TBM, the data from this SC study diverge from research conducted in Bahia in the 1980s and 1990s, which revealed that TBM involvement was more common among individuals less than or equal to 4 years of age, corroborating a study conducted in a rural community in Mozambique ${ }^{19}$. However, the results from this SC study support the results from the Tuberculosis Control Strategic Plan in Brazil 2007-2015 (Plano Estratégico de Controle de Tuberculose no Brasil 2007-2015) ${ }^{11}$, which states that in Brazil since 1996, there has been a sharp drop in the rates of TBM in children under 5 years of age. To some extent, this result can be attributed to the high levels of vaccination coverage $(100 \%)$ with BCG for children less than one year of age. Thus, TBM has ceased to be treated as a public health problem for children 5 years of age or less ${ }^{11}$.

Regarding education level, the highest TBM incidence rate was found among individuals who had completed 4 to 7 years of study $(0.05 / 100,000$ inhabitants), and the lowest incidence rate was found among individuals who had completed 1 to 3 years of study $(0.02 / 100,000$ inhabitants). These data reflect the possibility that with a low educational level, there is a greater awareness and better health habits for preventing the spread of $\mathrm{TB}$, as observed in the 1994 study in Bahia ${ }^{8-17}$.

Regarding the diagnostic criteria for confirming TBM cases, epidemiological linkage was most commonly used for reported cases $(19 \%)$, followed by the clinical signs $(17.2 \%)$, which are similar to data from the study in Salvador ${ }^{8-17}$. When noting the epidemiological linkage as a major criterion for the confirmation of cases, the data corroborate the results presented in another study that illustrates the potential for integration between the epidemiological surveillance and health services, not only as a data transfer chain but also regarding common goals to improve the quality of the health system with actions at the local level ${ }^{6}$.

Studies performed in Salvador, Bahia, in the 1990s regarding the incidence of TB in urban areas ${ }^{8-17}$ suggest an association between TB and the population concentration, justifying the 
predominance of the number of cases in more populous areas because the occurrence of TB is proportionally related to the increased TBM incidence. This finding corroborates the data observed in our study, which showed a higher proportion of reported cases in urban areas (91.4\%).

Regarding associations by racial group, our study revealed a predominance of reported cases among white individuals (69\%), followed by black individuals (12.1\%); this finding may be explained by the ethnic composition of our region, which is mostly composed of Caucasians.

Regarding the disease outcome, this study revealed that $48.3 \%$ of the patients died, and $50 \%$ were cured. Although slightly more patients recovered, the mortality rate is still high, most likely due to difficulties encountered by health services in the establishment of early treatment and diagnosis. Our findings confirm the severity of TBM, which had already been demonstrated in previous studies ${ }^{5,8,17}$ that revealed that more than $50 \%$ of affected patients died or were left with severe sequelae.

The available diagnostic methods do not possess the speed and sensitivity necessary for the precise and immediate introduction of a specific treatment $t^{4,5,8,14,17}$. This high mortality is consistent with the observed mortality rates in other developing countries, as described previously in Egypt in 1993 (54.7\%), in Chile in 1988 (32.6\%), and in India in 1985 (43.4\%) $)^{19,20}$.

Our study showed a bias in the analysis of the relationship between mortality by age because SINAN/MS only provided the absolute values for this information per year range for the period 2001-2010.

We conclude that the incidence rate of TBM has increased in $\mathrm{SC}$ in the last decade, with the most affected population being young adult white males with an average level of education and residing in urban areas. Thus, we can state that TBM remains a serious disease, emphasizing the need for disease prevention with vaccination campaigns against $\mathrm{TB}$, the development of faster and more accurate diagnostic methods, and the use of current epidemiological knowledge regarding the disease to facilitate the establishment of early treatment. Future research should investigate new mechanisms of drug resistance for improving TBM treatment. Because this investigation was an ecological study, future research should investigate the causes for the associations presented in this paper.

\section{CONFLICT OF INTEREST}

The authors declare that there is no conflict of interest.

\section{REFERENCES}

1. Victor M, Ropper AH. Principles of neurology. $7^{\mathrm{a}}$ ed. United States Of America: Mcgraw-Hill; 2001.

2. Honda H, Warren DK. Central nervous system infections: meningitis and brain abscess. Infect Dis Clin North Am 2009; 23:609-623.
3. Rowland LP. Merritt - Tratado de Neurologia. $11^{\mathrm{a}}$ ed. Rio de Janeiro: Guanabara Koogan; 2007.

4. Fundação Oswaldo Cruz (FIOCRUZ). Escola Nacional de Saúde Pública Sérgio Arouca. Procopio MJ, editor. Controle da tuberculose: uma proposta de integração ensino-serviço. Rio de Janeiro: EAD/ENSP, 2008; 348 p.

5. Christensen AS, Andersen AB, Thomsen VO, Andersen PH, Johansen IS. Tuberculous meningitis in Denmark: a review of 50 cases. BMC Infect Dis $2011 ; 11: 47$.

6. Escosteguy CC, Medronho RA, Madruga R, Dias HG, Braga RC, Azevedo OP. Vigilância epidemiológica e a avaliação da assistência às meningites. Rev Saude Publica 2004; 5:657-663.

7. Focaccia R, Veronesi R. Tratado de infectologia. $3^{\text {a }}$ ed. São Paulo: Atheneu; 2007.

8. Nunes C, Cunha S, Gomes I, Lucena R, Moraes D, Melo A. Fatores prognósticos de letalidade na meningoencefalite tuberculosa. Arq Neuro-Psiquiatr 1998; 56:772-777.

9. Marais S, Pepper DJ, Marais BJ, Török ME. HIV-associated tuberculous meningitis-diagnostic and therapeutic challenges. Tuberculosis (Edinb) 2010; 90:367-374

10. Davis LE. Infecções do Sistema Nervoso Central. In: Weiner WJ, Goetz CG, editors. Neurologia para o não-especialista. $4^{\text {a }}$ ed. São Paulo: Santos; 2003. p. 397-401.

11. Ministério da Saúde (MS). Secretaria de Vigilância em Saúde. Departamento de Vigilância Epidemiológica. Coordenação Geral de Doenças Endêmicas. Programa Nacional de Controle da Tuberculose. Plano Estratégico para o controle da tuberculose, Brasil 2007-2015. Brasília: MS; 2006, 43 p. [Cited 2014 March 13]. Available at: http:// www.paho.org/bra/index 2.php?option $=\mathrm{com} \_$docman\&task $=$doc_ view\&gid $=927 \&$ Itemid $=423$.

12. Johnson JL, Ellner JJ. Tuberculosis and atypical mycobacterial infections. In: Guerrant RL, Walker DH, Weller PF, editors. Tropical infectious diseases: principles, pathogens, and practice, $3^{\text {th }}$ ed. Elsevier; 2011. p. 228-247.

13. World Health Organization. Global tuberculosis control: WHO report 2011 [Internet]. Geneva: World Health Organization [cited 2014 Feb 11]. Available at: http://www.who.int/tb/publications/global_report/2011/ gtbrl1_full.pdf/.

14. Puccioni-Sohler M, Brandão CO. Factors associated to the positive cerebrospinal fluid culture in tuberculous meningitis. Arq Neuropsiquiatr 2007; 65:48-53.

15. Instituto Brasileiro de Geografia e Estatística. População residente, por sexo e situação do domicílio, população residente de 10 anos ou mais de idade, total, alfabetizada e taxa de alfabetização, segundo os Municípios. Rio de Janeiro: IBGE; 2011. [Cited 2014 May 17]. Available at http:// www.ibge.gov.br/home/estatistica/populacao/censo2000/universo. php?tipo $=31$ \&paginaatual $=1 \& u f=42 \&$ letra $=\mathrm{A} /$.

16. Sistema de Informação de Agravos de Notificação. Notas técnicas [Internet]. Brasília: Ministério da Saúde; 2011 [Cited 2014 March 13]. Available at: http://dtr2004.saude.gov.br/sinanweb/tabnet/dh?sinannet/ meningite/bases/meninbrnet.def/.

17. Nunes C, Cunha S, Gomes N, Tavares A, Amorim D, Gomes I, et al. Tuberculosis meningoencephalitis: exposure of 231 cases. Rev Soc Bras Med Trop 1998; 31:441-447.

18. Xavier MIM, Barreto ML. Tuberculose na cidade de Salvador, Bahia, Brasil: o perfil na década de 1990. Cad Saude Publica 2007; 23:445-453.

19. Chang CJ, Chang WN, Huang LT, Huang SC, Chang YC, Hung PL, et al. Bacterial meningitis in infants: the epidemiology, clinical features, and prognostic factors. Brain Dev 2004; 26:168-175.

20. Sigaúque B, Roca A, Sanz S, Oliveiras I, Martínez M, Mandomando I, et al. Acute bacterial meningitis among children, in Manhiça, a rural area in Southern Mozambique. Acta Trop 2008; 105:21-27. 